\title{
THE STATUS OF CONTENT REVISITED
}

BY

PAUL A. BOGHOSSIAN

In "The Status of Content" (hereafter, SOC), ${ }^{1}$ I proposed a particular way of formulating the thesis of content eliminativism-namely, as consisting in a thesis I called content irrealism. And I then proceeded to argue that, so formulated, content eliminativism is unstable. Since I took content irrealism to represent not only the traditional way, but also the most promising way known to me, of formulating the thesis of content eliminativism, I concluded that there was a prima facie difficulty with the coherence of content eliminativism. If I may be allowed to quote myself, I said:

... at least as traditionally formulated, an irrealism about content is not merely implausible, it is incoherent. The present paper is intended as a challenge, to those who wish to propound such an irrealism, to formulate their view in a manner that is not subject to the difficulties it raises. (p. 158)

In "Transcendentalism About Content," ${ }^{2}$ Michael Devitt presents a characteristically brisk critique of my paper. He expresses his main claim as follows:

I aim to show that all arguments to this effect are bad by laying bare the question-begging strategy that is common to them. (p. 247)

Unfortunately, his claims are based upon a serious misunderstanding of the argument of my paper. His most serious confusion can be succinctly stated: He thinks that content irrealism, as I defined it, is a thesis that is distinct from, and an optional elaboration upon, an antecedently articulated thesis of content eliminativism, rather than an expression of it. This causes havoc throughout his paper. Indeed, with a single exception to be discussed later, all his principal criticisms are based, and depend, upon this one simple mistake.

Pacific Philosophical Quarterly 71 (1990) 264-278

0279-0750/90/0400-0264\$1.50

Copyright (C) 1990 University of Southern California 
My aim in this paper is to argue a very narrow case: that Devitt's arguments don't show how to answer the challenge I laid down in SOC. ${ }^{3}$ I proceed as follows. I begin by looking at why I didn't formulate content eliminativism in the way that Devitt does, and why I did formulate it as the thesis of "content irrealism." I then show in detail why his criticisms are off-target.

\section{Eliminativism and Irrealism}

In SOC, I understood an 'eliminativism about P's' to consist in either one of the following theses:

(Error): The predicate 'is $\mathrm{P}$ ' denotes a property that nothing has.

Or,

(Non-factualism): The predicate 'is $\mathrm{P}$ ' does not denote any property.

Why define it so? Why not define it purely objectually in the manner Devitt evidently favors:

(Objectual Eliminativism): There are no P's.

We may all agree that an 'eliminativism about P's' is the view that nothing is P. But as the slightest knowledge of the history of the subject will reveal, philosophers have held that there are two importantly different ways in which it might transpire that there are no P's. One way is this: there is a property of being P, but nothing has it. There are no P's because nothing instantiates the property of being $\mathrm{P}$. One might take such a view about witches: there are no witches in the sense that nothing has the property of being a witch.

But another-historically very influential-way in which philosophers have wished to deny that there are P-facts is not by asserting that there is a property-P-ness - that nothing has, but rather by claiming something that might get expressed as follows: there is no such property as that of being $P$.

Thus, a moral non-cognitivist is an eliminativist about moral factsnot because he thinks that there are moral properties that nothing has, but because he thinks that there are no moral properties. Kripke's Wittgenstein is an eliminativist about semantic facts-not because he thinks that there are semantic properties that nothing has, but because he thinks that there are no semantic properties. And so on.

The problem for a purely objectual statement of eliminativism, how- 
ever, is that this important second sense in which one might be an eliminativist about P's does not appear to be coherently expressible as an objectual thesis. For how would it go? One might try:

There is no such property as that of being $\mathrm{P}$.

But it is hard to see how this is to be read as saying anything other than:

The property of being $\mathrm{P}$ is such that there isn't such a property.

And that couldn't be true.

The trouble is that the property whose existence (not whose instantiation) is being denied must be specified, if the claim is to be formulated at all; and yet not in terms that presuppose its existence. And I cannot see what coherent thought that is to be, if not a metalinguistic one. Namely, this:

The predicate 'is $\mathrm{P}$ ' does not refer to a property. ${ }^{4}$

This suggests that the root idea behind an 'eliminativism about P's' is really a thought of this form: No real properties answer to our use of the predicate 'is P.' And this thought itself seems expressible in the two ways that the (Error) and (Non-factualism) theses specify.

Exploiting familiar principles connecting reference and truth, we may write (Error) as:

(3) ' $\mathrm{X}$ is $P$ ' is always false ${ }^{5}$

and (Non-factualism) as:

(1) The predicate 'is P' does not refer to a property

and (hence)

(2) ' $x$ is $P$ ' does not express a truth condition. ${ }^{6}$

In SOC, I went on to point out that whereas (Non-factualism) would express an intelligible proposition only on robust readings of "truthcondition" and "refer," (3)-the general (Error) thesis-would express an intelligible proposition on either a robust or a deflationary conception of "false." " Since on a deflationary conception of "truth condition" and "refer," any declarative sentence is automatically truth-conditional, and any predicate automatically referential, (1) and (2) will always come out 
false on a deflationary reading. This is not true, however, for (3): (3) will yield distinct, apparently intelligible propositions, for each of the two possible readings of the truth (or falsity) predicate. Let's give them labels:

(3A) ' $x$ is $P$ ' is robustly false

and

(3B) ' $\mathrm{X}$ is $\mathrm{P}$ ' is deflationarily false.

Notice: Not only do (3A) and (3B) both appear to express intelligible propositions, they both appear to express intelligible propositions that are relevant to articulating the root thought behind 'eliminativism' (as I have explained it). In particular, since a deflationary falsity predicate is just a device for semantic ascent-a point stressed both by me and Devitt -(3B) just is the purely objectual proposition that no $\mathrm{X}$ is $\mathrm{P}$. So the relation between the 'eliminativism' that I define and the 'eliminativism' that Devitt defines-as consisting, namely, solely in (Objectual Eliminativism) - is that my definition subsumes his as part of a larger and fuller picture of the ideas that have been important in this area.

Aware of the fact that some people so regiment the term "eliminativism" that it is reserved for views that have purely objectual formulations, I decided in SOC to call the overall view defined by (Error) and (Non-factualism) "irrealism," rather than "eliminativism." This was a purely terminological decision. It was certainly not meant to suggest that irrealism is a thesis distinct from, and a further elaboration upon, an antecedently formulated 'eliminativism.' This should have been obvious from the first sentence of the paper, which Devitt cites:

An irrealist conception of a given region of discourse is the view that no real properties answer to the central predicates of the region in question. (p. 157)

Applied to the special case of an 'eliminativism about truth-conditional content,' the irrealist recipes above yield one or another of the following views. Either,

(Content Error): The predicate 'has truth condition p' refers to a property that nothing has.

Or,

(Content Non-factualism): The predicate 'has truth condition p' does not refer to any property. 
Exploiting familiar principles connecting reference and truth, we may write the first thesis as:

(4) All sentences of the form ' $\mathrm{S}$ has truth condition p' are false.

And the second as:

(5) The predicate 'has truth condition p' does not refer to a property

and

(6) 'S has truth condition p' is not truth-conditional.

And that is in fact the way I formulated content 'eliminativism' in SOC.

It is also the way many of the most prominent proponents of content eliminativism formulate their view - a fact that is amply documented in SOC and conveniently ignored by Devitt. Thus, to cite just four examples:

Paul Churchland:

our common sense psychological framework is a false and radically misleading conception of the causes of human behavior and cognitive activity. ${ }^{8}$

And Kripke (on behalf of Wittgenstein):

Wittgenstein's sceptical solution concedes to the sceptic that no 'truth conditions' or 'corresponding facts' in the world exist that make a statement like "Jones . . . means addition by '+" " true. ${ }^{9}$

And Stephen Stich:

The predicate 'is a belief that p' does not express or correspond to a property. ${ }^{10}$

And Ayer:

our analysis has shown that the word 'true' does not stand for anything. ${ }^{11}$

As these passages further reveal, the sort of content eliminativism that 'denies the existence of content properties' has been extremely influential in the history of the subject. And it is invariably expressed by its own proponents as I have argued it probably has to be: as a metalinguistic thesis. That is why I formulated eliminativism in general, and content eliminativism in particular, in the way that I did, and not in the manner of Devitt's terse purely objectual definition: 
(OCE) An eliminativist about truth-conditional content denies that anything has a content explained in terms of truth and reference. (p. 247)

To make matters as explicit as possible, let us now list the three versions of content irrealism that are on the table. Bearing in mind that an eliminativist about truth-conditional content is an eliminativist about robust-truth-conditional content only, ${ }^{12}$ and that there are two versions of the error thesis and only one of non-factualism, we get this:

(CNF, for content non-factualism): The predicate 'has robust-truth condition p' does not robustly-refer to a property; and the sentence 'S has robust-truth condition ' $\mathrm{p}$ ' is not robustly-truth-conditional.

( $\mathrm{RCE}$, for robust content error): ' $\mathrm{S}$ has robust-truth condition p' is always robustly-false.

(DCE, for deflationary content error): 'S has robust-truth condition p' is always deflationary-false. ${ }^{13}$

The purely objectualist view (OCE) is, of course, represented in this scheme by (DCE). So nothing would appear to have been left out.

\section{A Central Confusion}

Now in SOC, I went on to argue that none of these possible expressions of an irrealism about content appeared to express a stable proposition. Hence, there appears to be a prima facie difficulty with its coherence.

Devitt claims to find fault with my arguments. Here is what he does. First, he simply assumes at the outset that the only thesis that could legitimately be called an 'eliminativism about content' is the purely objectual thesis (OCE). Armed with this assumption, he fishes around for something else that my content irrealist theses might be taken to express. He decides that they must be expressions of "defect" thesestheses about a given sentence expressing the claim that it does not somehow meet our highest evaluative standards (see p. 251). Having arrived at this interpretation -in the teeth of what my paper actually says and of how eliminativists themselves formulate their views-he argues as follows.

First, it is true that (CNF) expresses an unstable proposition; but no content eliminativist would have anything to do with (CNF), for no content eliminativist would use (CNF) to express a "defect" thesis about the sentence ' $\mathrm{S}$ has robust-truth condition $\mathrm{p}$.' So it is entirely questionbegging to saddle her with (CNF). 
Second, it is true that (RCE) expresses an unstable proposition; but no content eliminativist would have anything to do with (RCE), for no content eliminativist would use (RCE) to express a "defect" thesis about the sentence 'S has robust-truth condition p.' So it is entirely questionbegging to saddle her with (RCE).

Third, there is nothing unstable with (DCE) and moreover no reason why a content eliminativist couldn't accept it: after all, it is just equivalent to her eliminativism. However, it is still wrong to suggest that she would use it to formulate a "defect" thesis about any sentence, for it is in general wrong to use a deflationary notion of falsity to formulate an error thesis about anything.

His arguments suffer from several problems.

First, my theses are not intended to be "defect" theses, formulated against the background of an antecedently stated content eliminativism, but rather formulations of the various distinct possible propositions that an eliminativism about content might amount to. My strategy in SOC was to show that each of these possible formulations of eliminativism is unstable; and to challenge the eliminativist to formulate her position in a way that doesn't commit her to them. Insofar, then, as Devitt concedes that two of these propositions are unstable, he concedes the only claim I ever made about them: that those particular avenues for expressing content eliminativism are closed. Insofar as he accuses me of inappropriately saddling the eliminativist with these theses as addenda to her eliminativism, he misinterprets me. Hence, his master charge-that my paper proceeds by saddling the eliminativist with theses that are "question-begging" - fails completely. It rests in its entirety on his failure to realize that the irrealist theses I defined are meant to be versions of eliminativism, not addenda to it. This failure constitutes his master confusion.

Second, Devitt's claim that my willingness to contemplate a deflationary reading of the (Error) thesis betrays a serious mishandling of deflationary truth, is based on the same misunderstanding. Since the (Error) thesis is not meant to be an expression of a "defect" thesis, but rather a version of eliminativism itself, and since the deflationary version of (Error) expresses a recognizably eliminativist thought (indeed the very thought that Devitt himself isolates as solely definitive of eliminativism), there would appear to be no mistake in my willingness to include it. On the contrary, I would have been delinquent to omit it.

Finally, he fails to appreciate that the argument against the coherence of (CNF) - which he concedes-already suffices to show the instability of (DCE) and, hence, of objectual content eliminativism itself.

I now turn to arguing for each of these claims in detail. 


\section{Devitt's Discussion of the Robust Error Thesis}

Devitt grants my claim that the thesis expressed by (RCE) is unstable. He argues, however, that it is in fact "naively" and "blatantly questionbegging" to suppose that the content eliminativist is committed to it. Hence, my claim that its instability weighs against content eliminativism fails.

Why does Devitt think that it is "question-begging" to suppose that the eliminativist is committed to (RCE)? This is puzzling, is it not? ( $R C E$ ) is supposed to be a statement of content eliminativism. How can the statement of a position beg its own question?

The answer is the master confusion: Devitt doesn't see that (RCE) is supposed to be a statement of eliminativism at all. Instead, he takes it to be a way of formulating a "defect" thesis about a sentence, framed against the background of an antecedently stated purely objectual eliminativist thesis. This comes through very clearly in the following passages:

The error thesis is a . . . semantic level doctrine made necessary by eliminativism at the metaphysical level. ... The thesis is supposed to give us explanatorily significant information about sentences, not simply to restate eliminativism. (p. 254)

And:

The essence of the error thesis about some sentences is that those sentences are open to criticism for not meeting our evaluative standards: they have a property that our "best" sentences don't; they are different from, say, the sentences of our most respected sciences. What defect we attribute to the sentences will depend on our semantics. If our semantics is truth-conditional, the defect in the sentences is obviously that they are false, as (3) says. If the semantics is the alternative one that the eliminativist must supply anyway, the defect will be something equally obvious. ... (pp. 251-252, emphases in original.)

On the basis of this simple oversight, he proceeds to convict me of begging the eliminativist's question by saddling her with (RCE). Armed with his fallacious assumption this is, of course, a very easy thing to do.

Why shouldn't we say that a content eliminativist-read, a proponent of (OCE)-will formulate her "defect" thesis about the sentence 'S has robust-truth condition p' as the view that:

( $\mathrm{RCE})$ 'S has robust-truth condition p' is always robustly-false?

Easy. For as Devitt is reading it, "content eliminativism" has been antecedently defined to consist solely in the objectual view: Nothing is robustly true or false. And, of course, nobody who already holds that view would say-in the course of formulating a "defect" thesis, or anything else for 
that matter-that the sentence ' $\mathrm{S}$ has truth condition p' is robustly false!

What this overlooks is that I was taking (RCE) to be a version of eliminativism itself, not a statement of a "defect" thesis additional to an antecedently formulated thesis of content eliminativism. It is not supposed to be the only version; it is not even supposed to be the most promising version. Just $a$ version, suggested by the general recipe for formulating the root through behind any eliminativist conviction whatever. And Devitt's concession that it is unstable concedes to me the only claim I ever made about it: namely, that at least this avenue for expressing content eliminativism is closed.

\section{Devitt's Discussion of the Non-Factualist Thesis}

Similar problems attend Devitt's discussion of my "non-factualist" variant. I defined a non-factualism about the sentence ' $x$ is $P$ ' to consist in (1) and (2) above. Devitt concedes my claim that this view, applied to the case of content ascriptions-yielding, as we have seen, (CNF)delivers an unstable proposition:

Boghossian argues that this account presupposes a robust notion of truth. On the strength of this, he is quickly able, not surprisingly, to convict the non-factualist about content ascriptions of "contradiction"....

However, this result is irrelevant, according to Devitt, because this account

is unsuitable for an eliminativist about content. Boghossian is saddling the eliminativist with precisely what she denies. (p. 258)

Why is this account unsuitable for an eliminativist about content? Devitt patiently explains:

Non-factualism about certain sentences is the view that those sentences have a different sort of meaning from the standard meaning of "factual" sentences, particularly the sentences of science. That is what is constitutive of non-factualism. Now, it is clear that a person whose standard semantics is truth-conditional will go on to identify non-factualism about sentences with the rejection of truth-conditional semantics for those sentences; he can go along with (1) and (2). But, it should be equally clear that a person who rejects truthconditional semantics altogether, and has a different standard semantics, will not accept (1) and (2) as an account of non-factualism. (p. 258)

The master confusion again: Devitt is assuming that the thesis I called "non-factualism" is supposed to be a "defect" thesis framed against the background of an antecedently defined, eliminativist thesis, purely 
objectually formulated. This time he pronounces it to be the view that certain "sentences have a different sort of meaning from the standard meaning of 'factual' sentences, particularly the sentences of science. That is what is constitutive of non-factualism." I, however, formulated (Non-factualism) to express a possible version of eliminativism itself-a version that, as we have seen, figures very prominently in the literature on the subject. And that is how I want it read.

On the basis of his misreading, he proceeds to convict me of begging the eliminativist's question. Why shouldn't we say that a content eliminativist-read, a proponent of (OCE)-will formulate her "defect" thesis about the sentence ' $S$ has robust-truth condition $p$ ' in terms of (CNF)? Easy. Since as Devitt understands it, a "non-factualism" about a sentence is supposed to express the idea that that sentence has a nonstandard semantics, and since a proponent of (OCE) holds that nothing has a robust truth condition, such a person will hardly want to use (1) and (2) to express "non-factualism," in general, or (CNF) to express content non-factualism in particular. Given the misunderstanding, the point is quite right.

Again, however, the criticism misfires. As I have already explained, a non-factualism about ' $x$ is $P$ ' is not supposed to be the view that ' $x$ is $P$ ' has a different meaning from the meaning of the sentences of science, but is supposed to be a statement-indeed, even a traditional statementof an important version of eliminativism about P's. In application to every other subject matter, it appears to yield a possible - not to say, plausible-view. In application to content ascriptions, I argued that it does not yield a possible view: (CNF) is intrinsically unstable. Devitt accepts this claim. He thereby concedes the only claim I ever made about it: that this-as we have seen very common-avenue for expressing content eliminativism is also closed. This strikes me as a very significant result.

\section{Devitt's Discussion of Deflationary Truth}

Devitt repeatedly complains about what he takes to be my misuse of a deflationary conception of truth:

Deflationary truth plays a major role in Boghossian's discussion of both the non-factualist thesis and the error thesis. . . . [But] deflationary truth has no place in the eliminativist's account of either form of irrealism. So deflationary truth is doubly irrelevant. . . (p. 252)

What we cannot go along with is what Boghossian does with deflationary truth. (p. 253)

Boghossian is seriously astray in his handling of deflationary truth. (p. 253) 
Again, however, the complaint rests on the simple confusion uncovered above, as we shall see.

Which claims of mine are the target of all this criticism? First, my claim that the general error thesis could be read with either a deflationary or a robust truth predicate. Second, my claim that the general nonfactualist thesis could be read only with robust notions of truth and reference.

What has Devitt so upset is that he finds my second claim here obvious, and my first claim false. Why? The master confusion again: because he is assuming that my error and non-factualist theses are attempts to formulate "defect" theses about sentences on the basis of a previously accepted eliminativist thesis, rather than attempts to state eliminativism itself.

Thus, he instructs us in the proper understanding of the idea of deflationary truth, patiently explaining that on this conception the truth predicate is just a device for semantic ascent, not something that can be used to attribute a property to a sentence. What he says merely rehearses remarks that I had myself made in characterizing deflationary truth (see SOC, pp. 162-163); but it is presented mysteriously as if it were news.

Armed with this elementary exposition of deflationary truth, and the fallacious assumption that my error and non-factualist theses are meant to be "defect" theses, rather than statements of content eliminativism itself, he proceeds to complain:

the deflationary falsity term cannot give us any explanatorily significant information about a sentence. In particular, it cannot tell us what the error thesis must tell us: the nature of the defect a sentence suffers from. Saying, as (3) does, that ' $x$ is $P$ ' is always false is saying that no $\mathrm{x}$ is $\mathrm{P}$. So it is simply a restatement of the metaphysical level doctrine eliminativism about P's. . . . [However] the thesis is supposed to give explanatorily significant information about sentences, not simply to restate eliminativism (p. 254)

And:

Boghossian discusses the notions of truth and reference in (1) and (2) at great length. ... He finds (1) and (2) hard to understand if their notions are merely deflationary. . . He concludes that the notions must be robust . . . But, of course, they must be robust if they are to characterize non-factualism. Deflationary truth cannot explain anything about sentences, only robust truth can do that. (p. 259)

Unfortunately for Devitt, however, the criticism misfires, owing to a distinct lack of target. As the reader is no doubt tired of being reminded, the theses are not meant to express "defect" theses, but rather various possible versions of eliminativism itself. It would have been wrong to leave out the deflationary reading of the general error thesis. That would 
have been to leave out not only a traditionally important version of eliminativism, but at the same time the only thesis that Devitt himself considers definitive of that view.

\section{The Argument Against the Deflationary Error Thesis}

What, then, about the deflationary error thesis or, equivalently, Devitt's objectual view: Nothing has a robust-truth-conditional or robust-referential property?

Let's go back to the discussion of content non-factualism. This is the thesis that:

(CNF): The predicate 'has robust truth-condition p' does not robustlyrefer to any property; and, the sentence 'S has robust-truth condition p' is not robustly-truth-conditional.

As the reader may recall, I argued in SOC-and Devitt concedes-that this thesis does not express a stable proposition. In fact, in SOC I went further and argued that neither conjunct by itself expresses a stable proposition. None of those claims is challenged by Devitt.

Now, Devitt is not disturbed by these results because he thinks that a content eliminativist is not committed to (CNF). And he thinks that a content eliminativist is not committed to $(\mathrm{CNF})$ for two reasons: first, because he understands content eliminativism to consist solely in the purely objectual thesis (OCE); and because he understands (CNF) to be the view that content ascriptions are not like the sentences of science. And he argues, rightly, that no one who holds (OCE) will use (CNF) to express the view that content ascriptions are not like the sentences of science.

Let's grant this. Let's grant that a proponent of (OCE)-the sort of content eliminativist who is up for discussion in this section-will never use (Non-factualism) in general, or (Content non-factualism) in particular, to express the view that some sentence has a "non-scientific" meaning.

It doesn't follow, however, that the proponent of (OCE) is not committed to (CNF). In fact, and on the contrary, a proponent of (OCE)Devitt's sort of content eliminativist-is very much committed to (CNF)!

For look: A Devittian content eliminativist is someone who denies that anything has a robust-truth-conditional or a robust-referential property. $A$ fortiori, she denies that the predicate 'has robust-truth condition p' robustly-refers to a property, and denies that the sentence ' $\mathrm{S}$ has a robusttruth condition p' has a robust-truth condition. She would appear to be committed to these claims regardless of what she would or would not call 
them! But these claims just are (CNF). And yet I argued-and Devitt accepts - that (CNF) leads to a contradiction. ${ }^{14}$

\section{The Austere Eliminativist}

Finally, what about Devitt's "austere eliminativist"-the philosopher who "denies that anything is true or false in any sense," including a deflationary one? (p. 251) As the reader may recall, this position comes up in the course of Devitt's contention that my formulation of the general (Error) thesis-construed as a "defect" thesis-begs the question against the eliminativist. This claim, of course, rests on the master confusion. But we should still ask how the arguments of SOC bear on this position, especially as Devitt proclaims that "austere eliminativism is coherent and would be left totally untouched by Boghossian's argument." (p. 251)

The answer is that they bear on it in an especially direct way, as the slightest reflection will reveal. The austere eliminativist denies that anything is true or false in any sense. So her position is a conjunction of claims: nothing is robustly truth-conditional and nothing is deflationarily truth-conditional-robust eliminativism and deflationary eliminativism. I have just finished showing how the arguments of SOC militate against the robust eliminativist. These arguments will, of course, carry over to the austere eliminativist. But the austere eliminativist suffers from a further problem, a problem generated by the second conjunct in her view - that nothing is even deflationarily truth-conditional.

An essential component in my argument against (CNF) - which as we saw, Devitt accepts-is the following claim: Denying "truth-conditionality" of a declarative sentence only makes sense on a robust understanding of "truth-conditional;" on a deflationary conception such a claim will always come out false, for on a deflationary conception any declarative sentence is automatically truth-conditional. Understanding this feature of deflationary truth is a sine qua non of understanding it at all. This is a point that is stressed equally by me and Devitt (see his discussion of deflationary truth).

But now there would appear to be a transparent problem for the deflationary eliminativist. For the deflationary eliminativist denies that anything is deflationarily truth-conditional; a fortiori, she denies that declarative sentences (' $\mathrm{S}$ has deflationary-truth-condition $\mathrm{p}$,' 'Grass is green,' etc.) are deflationarily truth-conditional. But as I argued in SOC -and as Devitt accepts - it is impossible for a declarative sentence to fail to be deflationarily truth-conditional. So the view looks to be necessarily false-the betrayal of a mere confusion about the nature of deflationary truth. 


\section{Conclusion}

Devitt says that his aim in "Transcendentalism About Content" is to show that all arguments to the effect that content eliminativism is unstable "are bad, by laying bare the question-begging strategy that is common to them." He would appear to have fallen well short of his aim.

First, even if his criticisms of my paper had not been so off-target, I don't see how his arguments could be counted upon to generalize to any conceivable argument to this effect that someone might dream up. Could it be that he is being myopic here?

Second, and more importantly, his criticisms of my paper grossly misfire. Insofar as he concedes that (RCE) and (CNF) are unstable, he concedes the only claim I ever made about them: namely, that those particular avenues for expressing content eliminativism are closed. Insofar as he criticizes me for inappropriately saddling the content eliminativist with these theses, and accuses me of mishandling the idea of deflationary truth, he misinterprets me. Insofar as he claims that my arguments do not bear on the austere content eliminativist, he both misinterprets me and fails to think matters through. Finally, his criticism of my argument against the deflationary error thesis is strictly correct, but fails to appreciate that all that it calls for is a slight redeployment of the argumentative resources of SOC.

SOC posed a challenge to content eliminativists. As far as I am able to judge, Devitt's paper leaves that challenge unanswered. There remain many difficult issues in this area and many aspects of the arguments I presented that require further discussion. But these matters are best left for another occasion. ${ }^{15}$

University of Michigan

Ann Arbor, Michigan

\section{NOTES}

1 The Philosophical Review, 99 (1990): 157-184.

2 This journal, this issue. All references to Devitt are to this paper.

3 I have had a number of interesting reactions to SOC. My original plan had been to wait until a sufficient number of them had come in, and then to respond to some of the more important points raised in them in the context of a fuller discussion of the argumentative strategies pursued in SOC. Devitt's paper has forced me to depart from my original plan. I felt it would be unwise to let such a serious misrepresentation of my paper circulate unanswered.

${ }^{4}$ Ultimately, nothing really hangs on whether there is or isn't an objectual way of formulating this sort of eliminativism. I don't know how to do it satisfactorily; nor do I know of anyone else who does. So in SOC I followed common custom and formulated it 
metalinguistically. But if the points made toward the end of this paper are sound, not even this is strictly needed.

5 Here and below I am following the numbering of SOC.

6 For further discussion see SOC. Just for the record, (2) is not strictly needed for the arguments that follow. It would be enough if (Non-factualism) were defined so as to consist solely in (1).

7 This point could have been made directly on (Error) and (Non-factualism) rather than on their truth-theoretic variants.

8 Paul Churchland, Matter and Consciousness (Cambridge, Mass.: The MIT Press, 1984), p. 43.

9 Saul Kripke, Wittgenstein on Rules and Private Language (Cambridge, Mass.: Harvard University Press, 1982), p. 86.

10 Stephen Stich, From Folk Psychology to Cognitive Science: The Case Against Belief (Cambridge, Mass.: The MIT Press, 1983), pp. 225-226.

11 A. J. Ayer, Language, Truth and Logic (New York, N.Y.: Dover Publications, 1952), p. 107.

12 This deliberately leaves out Devitt's "austere eliminativist," the person who denies that anything is true or false in any sense, even a deflationary one. It will prove convenient to set this marginal position aside for now. It doesn't affect anything that follows. At the end of the paper I will show how it introduces no new issues for the argumentative strategy pursued by SOC.

13 To help make matters as clear as possible, I have introduced the hyphenated predicates, "robust-truth" and "deflationary-truth," and their variants. Here I am following Devitt's recommendation (see his note 17 and pp. 256-257), so this is not something he is in a position to object to. However, let me here record my belief that the introduction of such predicates, in the present context, is not an unproblematic matter. This is a delicate issue that cannot be discussed within the confines of the present essay, and so for the sake of expediency, I will suppress any worries on this score.

14 It's one of the many mysteries in this area that an objectual eliminativism about content should entail a non-factualism about content. This doesn't happen in the case of any other subject matter. It's one of the many clues we have that our usual expressions of irrealism are subject to unexpected twists when they are turned upon the semantic notions themselves.

The argument presented here was not properly in focus when I wrote SOC. Certainly my presentation in SOC assimilated the discussion of the deflationary error thesis too much to the discussion of the robust error thesis. Devitt is right to object that the argument against the one won't work on the other. However, this merely calls for a slight redeployment of the argumentative resources of SOC. For prompting me to get clearer about this, I am grateful to Devitt's paper.

15 For helpful discussion or comments, I am grateful to Paul Horwich, Jerry Fodor, Barry Loewer, Jennifer Church, and Mark Kalderon. As always, special thanks to David Velleman. 